\title{
Management of Brown Recluse Spider Bites in Primary Care
}

\author{
James W. Mold, MD, MPH, and David M. Thompson, PhD
}

Background: Treatment of brown recluse spider bites remains controversial; there are multiple options but little evidence of their effectiveness.

Methods: Over a 5-year period, family physicians enrolled consecutive patients with suspected brown recluse spider bites. Usual care was provided based on physician preferences. Topical nitroglycerine patches and vitamin $C$ tablets were provided at no cost for those who wished to use them. Baseline data were collected, and patients were followed-up weekly until healing occurred. Outcome measures included time to healing and occurrence of scarring. Regression methods were used to evaluate the impact of the 4 main treatment approaches (corticosteroids, dapsone, topical nitroglycerine, and highdose vitamin C) after controlling for bite severity and other predictors.

Results: Two hundred and sixty-two patients were enrolled; outcomes were available for 189. The median healing time was 17 days. Only $21 \%$ had permanent scarring. One hundred seventy-four received a single treatment modality. Among this group, 12 different modalities were used. After controlling for other variables, predictors of more rapid healing included lower severity level, less erythema, and less necrosis at time of presentation, younger age, no diabetes, and earlier medical attention. Systemic corticosteroids and dapsone were associated with slower healing. Predictors of scarring were higher severity, presence of necrosis, and diabetes. Dapsone was associated with an increased probability of scarring.

Conclusions: We found no evidence that commonly used treatment approaches reduced healing time or the likelihood of scarring in suspected brown recluse spider bites. (J Am Board Fam Pract 2004;17: 347-52.)

Loxosceles reclusa, also known as the brown recluse or "fiddleback" spider, is a common inhabitant of homes and yards in the southwestern United States. Related species occur in temperate regions throughout the world. Bites generally occur when the victim inadvertently comes into physical contact with the spider while sleeping, moving boxes, firewood, etc, or getting dressed. Although most bites heal within 3 weeks without necrosis or scarring, approximately 20\% develop necrotic ulcers that may take months to heal and often result in permanent scarring. ${ }^{1}$ A few bites trigger serious systemic reactions including hemolysis, methemo-

Submitted, revised, 15 March 2004.

From the Departments of Family and Preventive Medicine (JWM) and Biostatistics and Epidemiology (DMT), University of Oklahoma Health Sciences Center, Oklahoma City. Address correspondence to James W. Mold, MD, MPH, University of Oklahoma Health Sciences Center, 900 NE 10th Street, Oklahoma City, OK (e-mail: jamesmold@ouhsc.edu). globinemia, rhabdomyolysis, hemoglobinuria, platelet aggregation, and renal failure. ${ }^{2-5}$

Local and systemic reactions to brown recluse spider bites are caused by the body's reaction to the toxins produced by the spider, primarily sphingomyelinase $\mathrm{D}$, which becomes incorporated into cell membranes in the skin and subcutaneous tissue, triggering an inflammatory response mediated by the ceramide phosphate pathway. One researcher has reported that Clostridium perfringens can be cultured from the fangs and venom of the spider in a significant number of cases, suggesting the possibility that secondary infection may play a role in some cases. ${ }^{6}$ Histological examination reveals a mixed inflammatory cell infiltrate, coagulative tissue necrosis, and vasculitis. ${ }^{7,8}$ The complement system may be inactivated. ${ }^{9}$ The response persists until the toxin is lysed, metabolized, and removed from the body.

A variety of treatment approaches have been suggested. These include conservative treatment 
with heat, ice, and/or elevation; corticosteroids applied topically or administered by local or systemic injection; dapsone; topical nitroglycerine applied directly over the bite; high-dose vitamin C; direct electrical current; antihistamines; and proteolytic enzymes (eg, meat tenderizer).

Clinical diagnosis and research have been hampered by the lack of a commercially available diagnostic test. Randomized, controlled trials in rabbits have demonstrated benefit from intralesional antiLoxosceles Fab fragments, ${ }^{10}$ a small benefit from hyperbaric oxygen in 2 studies but no effect in another, and no effect of dapsone, cyproheptadine, or topical nitroglycerine. ${ }^{11-14}$ A controlled trial in guinea pigs showed some benefit of dapsone but no benefit of electric shock therapy. ${ }^{15}$ We found no randomized, controlled human clinical trials in the English language literature.

The purpose of this epidemiologic study was to gather more information about the nature and course of brown recluse bites seen by primary care clinicians and to determine whether any of the commonly used treatments showed sufficient promise to justify a clinical trial in humans.

\section{Methods}

Between May 1995 and October 2000, family physician members of the Oklahoma Physicians Resource/Research Network (OKPRN) were asked to enroll consecutive patients with suspected brown recluse spider bites in this prospective epidemiologic study. They were provided with 2 returnaddressed data collection cards. On card A the physician, the nurse, and the patient recorded baseline information about the patient and the bite. A metric ruler provided to the clinicians was used to determine the diameters of erythema, induration, and necrosis at the time of presentation. Physicians were asked to see or, if that was impossible, to talk on the phone with enrolled patients once weekly thereafter until the bite healed. A tear-off tab on card A was kept as a reminder for follow-up contacts. The date the bite was judged to be healed and an assessment of whether permanent scarring would result from the bite were recorded on card B. Clinicians were also asked to estimate the probability that the lesion was a brown recluse spider bite on both card A (prospectively) and card B (retrospectively). Clinicians were educated about brown recluse spiders and the typical appearance of its bite before the study.
Specific written definitions were provided for all variables. Wounds were considered "healed" when they were "fully epithelialized and signs of inflammation [had] subsided." "Scarring" was defined by the question, "Based on your best judgment, is this bite going to leave a noticeable permanent scar or other form of disfigurement?" "Conservative treatment" was defined as any one or more of the following: expectant observation, cool compresses, elevation, exercise avoidance, immobilization, and cleansing. "Bite severity" (mild, moderate, severe) was left to the judgment of the clinician.

Between May 1998 and October 2000, in response to a report of a series of cases successfully treated with topical nitroglycerine and the subjective opinion of local "experts" that high-dose vitamin $C$ was effective, ${ }^{16}$ participating physicians and their patients who wished to try them were provided with free samples. All patients treated with either nitroglycerine or high-dose vitamin C during the study used the free samples. The University of Oklahoma Health Sciences Center's Institutional Review Board approved all aspects of the study, and all participating patients signed informed consent documents.

Linear regression was used to model the associations between the natural logarithm of healing time and the 4 main treatment regimens, corticosteroids (local or systemic injection), dapsone, topical nitroglycerine, and high-dose vitamin C. We transformed healing time (in days) to its natural logarithm because doing so produced more normal regression residuals and therefore improved our confidence in model results. A grouped stepwise approach was used to enter and eliminate independent variables using $P<.2$ for entry and $P<.05$ for retention as follows. The 4 individual treatment approaches were considered first, then demographic variables, such as patient age, race, and gender, then diabetes and prebite (ongoing) treatment with nonsteroidal anti-inflammatory medications or corticosteroids, and finally bite characteristics, including location, severity, and treatment delay. Using similar methods, logistic regression was used to model the relationships between the independent variables and presence or absence of permanent scarring. Both regression models were then reconstructed for patients whose bites were prospectively judged to be probable or definite brown recluse spider bites. All analyses were preformed using SAS 8.01 (SAS Institute, Cary, NC). 
Physicians could choose to treat with all, some, or none of the available treatments. However, recognizing that it was unusual for physicians to use more than 2 different primary forms of treatments with or without conservative management or antibiotics, we examined a single primary treatment variable with 4 values; systemic and/or locally injected corticosteroids, dapsone, high-dose Vitamin $\mathrm{C}$, and topical nitroglycerine. We represented these 4 treatments by using 4 dummy variables in the regression models, comparing them with conservative treatment (which could include antibiotics). Because only 15 patients received more than one treatment, we restricted the analysis to the 174 who received either a single treatment or conservative care only (including antibiotics). Doing so removed the possibility that results could be biased by uncharacterized interactions between treatments.

Analysis of variance using the same variables plus a term for patients nested within clinic was used to examine the possibility of a physician effect on outcomes. Interactions between variables were also investigated.

\section{Results}

During the 5-year study period, 44 clinicians from 23 different practices enrolled 254 patients in the study. Outcome measures were available for 189. Patients lost to follow-up did not differ on any of the baseline variables from patients for whom outcome data were obtained. The mean age \pm S.D. of enrolled patients was $38.4 \pm 17.8$. Table 1 lists the independent and dependent variables, their ranges, and measures of their central tendencies among the enrolled participants. These data include and extend data on the first 149 cases published previously. ${ }^{1}$

Patients were seen, on average, $3.2 \pm 3.48$ days after the bite, at which time examination revealed a mean of $6.0 \pm 5.5 \mathrm{~cm}$ of erythema and $0.36 \pm 0.68$ $\mathrm{cm}$ of necrosis. The mean healing time \pm S.D. was $22.1 \pm 18$ days, and the median and range of healing times was 17 days and 1 to 144 days, respectively. Table 2 shows the number of patients treated with each of 12 methods for whom outcome data were available, comparing bite severity (decimeters of erythema and necrosis) at the time of enrollment and the outcomes (healing time and scarring) observed for each treatment group. $\mathrm{Pa}$ -
Table 1. Baseline Characteristics of Enrolled Patients

$(\mathrm{N}=256)$

\begin{tabular}{|c|c|}
\hline Characteristic & Percentage \\
\hline $\begin{array}{l}\text { Age group } \\
0 \text { to } 9 \\
10 \text { to } 19 \\
20 \text { to } 44 \\
45 \text { to } 64 \\
\geq 65\end{array}$ & $\begin{array}{r}5 \\
12 \\
45 \\
31 \\
7\end{array}$ \\
\hline $\begin{array}{l}\text { Gender } \\
\text { Male } \\
\text { Female }\end{array}$ & $\begin{array}{l}38 \\
62\end{array}$ \\
\hline Spider identified by credible witness or clinician & 13 \\
\hline Brown recluse spiders seen in vicinity & 57 \\
\hline $\begin{array}{l}\text { Season when bite occurred } \\
\text { Winter } \\
\text { Spring } \\
\text { Summer } \\
\text { Fall }\end{array}$ & $\begin{array}{r}9 \\
37 \\
40 \\
14\end{array}$ \\
\hline $\begin{array}{l}\text { Place where bite occurred } \\
\text { Indoors } \\
\text { Outdoors } \\
\text { No idea }\end{array}$ & $\begin{array}{l}56 \\
20 \\
24\end{array}$ \\
\hline $\begin{array}{l}\text { Location of bite } \\
\text { Arm } \\
\text { Leg } \\
\text { Trunk } \\
\text { Head }\end{array}$ & $\begin{array}{r}27 \\
45 \\
19 \\
9\end{array}$ \\
\hline $\begin{array}{l}\text { Severity (clinician rating) } \\
\text { Mild } \\
\text { Moderate } \\
\text { Severe }\end{array}$ & $\begin{array}{l}34 \\
56 \\
10\end{array}$ \\
\hline $\begin{array}{l}\text { Initial probability that lesion was brown recluse } \\
\text { spider bite } \\
\text { Possible } \\
\text { Probable or definite }\end{array}$ & $\begin{array}{l}28 \\
72\end{array}$ \\
\hline Previous brown recluse bite & 12 \\
\hline Diabetes mellitus & 5 \\
\hline Use of NSAID at time of bite & 7 \\
\hline Patient felt the bite when it occurred & 15 \\
\hline $\begin{array}{l}\text { Local symptoms/signs at enrollment } \\
\text { Pain } \\
\text { Itching } \\
\text { Tenderness } \\
\text { Blister or vesicles } \\
\text { Necrosis }\end{array}$ & $\begin{array}{l}66 \\
64 \\
75 \\
29 \\
39\end{array}$ \\
\hline $\begin{array}{l}\text { Systemic symptoms/signs at enrollment } \\
\text { Symptoms } \\
\text { Signs }\end{array}$ & $\begin{array}{l}28 \\
14\end{array}$ \\
\hline
\end{tabular}

tients lost to follow-up did not differ significantly from those with outcome data on any measured characteristic.

In these univariate analyses, physicians prescribed topical corticosteroids for less severe bites and treatment with antihistamines was associated with a reduced risk of scarring. However, in the multivariate analyses (Table 3), no treatment modality was found to be associated with reduced healing times or lower rate of scarring. Use of 
Table 2. Study Population by Treatment Group Showing Mean (S.D.) Baseline Severity and Outcomes for Each $(\mathrm{N}=189)$

\begin{tabular}{|c|c|c|c|c|}
\hline $\begin{array}{l}\text { Treatments } P \text {-value for } \\
\text { between Group Differences }\end{array}$ & $\begin{array}{l}\text { Erythema } \\
\text { Diameter } \\
\quad(\mathrm{cm})\end{array}$ & $\begin{array}{c}\text { Necrosis } \\
\text { Diameter }(\mathrm{cm})\end{array}$ & $\begin{array}{l}\text { Healing Time } \\
\text { (from Time of } \\
\text { Bite in Days) }\end{array}$ & $\begin{array}{c}\text { Percentage } \\
\text { Resulting } \\
\text { in Scarring }\end{array}$ \\
\hline \multicolumn{5}{|l|}{ Conservative* $^{*}$} \\
\hline Yes $(\mathrm{N}=121)$ & $5.8(5.3)$ & $0.39(0.71)$ & $23.0(20.9)$ & 23.0 \\
\hline No $(\mathrm{N}=68)$ & $5.6(5.5)$ & $0.34(0.66)$ & $20.5(14.7)$ & 17.5 \\
\hline$P$ value & .76 & .61 & .36 & .36 \\
\hline \multicolumn{5}{|l|}{ Meat tenderizer } \\
\hline Yes $(\mathrm{N}=4)$ & $4.0(1.7)$ & $0.63(1.3)$ & $6(1.4)$ & 0 \\
\hline No $(\mathrm{N}=185)$ & $5.7(5.4)$ & $0.36(0.72)$ & $21.8(17.9)$ & 20.2 \\
\hline$P$ value & .13 & .70 & .21 & .61 \\
\hline \multicolumn{5}{|l|}{ Antihistamine } \\
\hline Yes $(\mathrm{N}=56)$ & $6.8(5.9)$ & $0.25(0.74)$ & $19.0(13.6)$ & 7.3 \\
\hline No $(\mathrm{N}=133)$ & $5.4(5.2)$ & $0.39(0.72)$ & $22.4(18.9)$ & 23.8 \\
\hline$P$ value & .09 & .19 & .20 & .02 \\
\hline \multicolumn{5}{|l|}{ Dapsone } \\
\hline Yes $(\mathrm{N}=42)$ & $6.7(5.5)$ & $0.42(1.0)$ & $25.0(13.5)$ & 29.0 \\
\hline No $(\mathrm{N}=147)$ & $5.5(5.4)$ & $0.35(0.65)$ & $21.0(18.6)$ & 18.3 \\
\hline$P$ value & .19 & .69 & .15 & .17 \\
\hline \multicolumn{5}{|l|}{ DC Current } \\
\hline Yes $(\mathrm{N}=6)$ & $6.6(4.2)$ & $0.75(0.88)$ & $28.2(27.1)$ & 16.7 \\
\hline No $(\mathrm{N}=183)$ & $5.7(5.4)$ & $0.35(0.72)$ & $21.4(17.5)$ & 20.2 \\
\hline$P$ value & .69 & .19 & .57 & .83 \\
\hline \multicolumn{5}{|l|}{ High-dose Vitamin C } \\
\hline Yes $(\mathrm{N}=14)$ & $6.8(5.8)$ & $0.38(0.60)$ & $29.8(23.7)$ & 44.5 \\
\hline No $(\mathrm{N}=175)$ & $5.6(5.4)$ & $0.36(0.74)$ & $21.2(17.5)$ & 18.9 \\
\hline$P$ value & .43 & .94 & .16 & .06 \\
\hline \multicolumn{5}{|l|}{ Systemic corticosteroids } \\
\hline Yes $(\mathrm{N}=76)$ & $6.0(6.0)$ & $0.28(0.59)$ & $24.9(19.0)$ & 17.0 \\
\hline No $(\mathrm{N}=113)$ & $5.6(5.2)$ & $0.40(0.78)$ & $20.3(17.3)$ & 21.5 \\
\hline$P$ value & .55 & .17 & .12 & .49 \\
\hline \multicolumn{5}{|l|}{ Local injection corticosteroids } \\
\hline Yes $(\mathbf{N}=13)$ & $3.6(2.1)$ & $0.29(0.31)$ & $19.8(11.6)$ & 30 \\
\hline No $(N=176)$ & $5.8(5.5)$ & $0.37(0.74)$ & $21.8(18.2)$ & 19.5 \\
\hline$P$ value & .002 & .40 & .73 & .42 \\
\hline \multicolumn{5}{|l|}{ Topical corticosteroids } \\
\hline Yes $(\mathrm{N}=12)$ & $3.7(2.7)$ & $0.08(0.13)$ & $17.9(12.6)$ & 10.0 \\
\hline No $(\mathrm{N}=177)$ & $5.8(5.5)$ & $0.38(0.74)$ & $21.9(18.1)$ & 20.7 \\
\hline$P$ value & .02 & $<.0001$ & .50 & .41 \\
\hline \multicolumn{5}{|l|}{ Systemic antibiotics } \\
\hline Yes $(\mathrm{N}=152)$ & $6.0(5.5)$ & $0.42(0.78)$ & $21.8(15.0)$ & 21.4 \\
\hline No $(\mathrm{N}=37)$ & $5.3(5.2)$ & $0.28(0.64)$ & $21.4(21.5)$ & 18.1 \\
\hline$P$ value & .31 & .11 & .87 & .58 \\
\hline \multicolumn{5}{|l|}{ Topical antibiotics } \\
\hline Yes $(\mathrm{N}=50)$ & $5.4(3.9)$ & $0.51(0.81)$ & $22.7(23.1)$ & 26.3 \\
\hline No $(\mathrm{N}=139)$ & $6.2(5.8)$ & $0.32(0.64)$ & $21.4(16.3)$ & 18.5 \\
\hline$P$ value & .32 & .20 & .75 & .28 \\
\hline \multicolumn{5}{|l|}{ Topical nitroglycerine } \\
\hline Yes $(N=24)$ & $6.7(4.8)$ & $0.34(0.61)$ & $24.2(19.4)$ & 28.6 \\
\hline No $(\mathrm{N}=165)$ & $5.6(5.5)$ & $0.37(0.74)$ & $21.3(17.7)$ & 19.0 \\
\hline$P$ value & .30 & .87 & .49 & .30 \\
\hline
\end{tabular}

${ }^{*}$ Conservative treatment included any one or more of the following: expectant observation, cool compresses, elevation, exercise avoidance, immobilization, and/or cleansing.

systemic corticosteroids and dapsone were associated with longer healing times (by $45 \%$ and $28 \%$, respectively), and dapsone was associated with a $45 \%$ greater risk of scarring. In fact, the linear regression coefficients were positive (longer healing time) for all treatments except topical antibiotics, although only dapsone and corticosteroid use reached statistical significance. Patients with diabetes had healing times that were $73 \%$ longer than those with no diabetes history. Age increased healing time by $10 \%$ per decade, erythema diameter by $2 \%$ per centimeter, and treatment delay by $8 \%$ per day. The presence of necrosis was not always predictive of permanent scarring, but it did increase 
Table 3. Multivariate Models for the Two Outcome Measures Treatment Options Considered As Independent

Variables $(\mathrm{N}=174)$

\begin{tabular}{|c|c|c|}
\hline Variables & 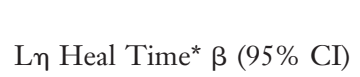 & $\begin{array}{c}\text { Scarring } \\
\text { Odds Ratio }(95 \% \mathrm{CI})\end{array}$ \\
\hline Dapsone & $0.37(0.05,0.70)$ & $4.27(1.05,17.44)$ \\
\hline Systemic corticosteroids & $0.25(0.004,0.50)$ & NS \\
\hline Erythema diameter $(\mathrm{cm})$ & $0.02(0.004,0.04)$ & NS \\
\hline Necrosis (yes/no) & NS & $4.60(1.69,12.53)$ \\
\hline Severity (severe) & NS & $7.45(2.12,26.14)$ \\
\hline Treatment delay (days) & $0.08(0.05,0.11)$ & NS \\
\hline Age & $0.010(0.004,0.02)$ & NS \\
\hline Diabetes mellitus & $0.55(0.08,1.01)$ & NS \\
\hline
\end{tabular}

* For the linear regression model, $\mathrm{R}^{2}=0.3667$ and adjusted $\mathrm{R}^{2}=0.3295$

NS, not significant.

the probability of scarring by $53 \%$. The results were nearly identical when only the 121 patients with "probable" or "definite" brown recluse bites were included, except that the effects of age and dapsone on natural logarithm-adjusted healing time were no longer statistically significant.

The effect of nesting patients within practice location was not found to be significant $(P=.1061)$ in an analysis of variance that included all the other factors listed in Table 3. Therefore, the final regression model does not include an effect for clinicians on the outcome variables. No interactions were identified between variables remaining in the models.

\section{Discussion}

This is, to our knowledge, the largest series of brown recluse spider bites reported in the literature. It is probably representative of the kinds of bites seen by family physicians in their offices. The results provide baseline information that could be used to design clinical trials or to compare with the results of case series. Unfortunately, we did not identify a treatment approach that was sufficiently promising to warrant a clinical trial in humans at this point.

The study has several weaknesses. We have no way of knowing what percentage of the lesions were actually brown recluse spider bites. However, because there is still no clinically available diagnostic test, the question facing family physicians is how they should manage lesions they think might be spider bites. Therefore our study population is probably the appropriate one. It is also reassuring that the subset of patients with lesions judged ret- rospectively to have probably or definitely been brown recluse spider bites $(\mathrm{N}=133 ; 71.1 \%$ of all bites), did not differ significantly in their response to treatment or with respect to the other outcome predictors.

We do not know the proportion of patients with suspected bites who were not enrolled in the study (nonparticipants), and a substantial number of enrolled patients (28\%) were lost to follow-up. Those lost to follow-up did not differ in any measured respect from those who remained in the study.

We tried to collect as much information as possible about the severity of the bites. However, patients were seen, on average, 3.5 days (range, 0.5 to 38 days) after the bite, and we were unable to find an acceptable way to adjust diameter of erythema and necrosis to account for differences in the age of the wound. In the end, we were able to explain only $37 \%$ of the variability in healing time.

Because we had no control over the treatments chosen, some were used infrequently. As a result, we can say little about the effectiveness of meat tenderizer, direct electrical current, local injection of corticosteroids, or topical corticosteroids. Because systemic corticosteroids seemed to be harmful, and because the form of inflammation induced by sphingomyelinase D is not likely to be corticosteroid-responsive, it seems unlikely that locally injected or topically administered corticosteroids would be helpful.

The association between treatment delay and healing time is interesting because none of the recorded treatments seemed to have a beneficial effect. One explanation is that the clinicians were doing something of value that was not recorded as 
treatment (eg, reassurance). Another is that there is something different about bites that take longer to heal (eg, delayed inflammatory response). A third is that there is something different about patients who delay seeking treatment for spider bites (eg, generally in poorer health).

Despite the exploratory nature of this study, we believe that its results suggest that family physicians can confidently withhold several commonly used treatments from patients with suspected brown recluse spider bites.

We acknowledge the following clinicians for their assistance and support in this study: Michael Aaron, MD, Weatherford, OK; Noble Ballard, MD, Altus, OK; Bill Boundurant, MD, Joe Jamison, MD, Edmond Physicians, Edmond, OK; JoAnn Carpenter, MD, Ada, OK; Roger Elliot, PA-C, Physician Assistant Program, Oklahoma City; Ed Farrow, MD, Eufaula, OK; Cary Fisher, MD, Northwest Family Medicine, Oklahoma City; Ronald Fried, MD, Wewoka Indian Health Center, Wewoka, OK; Mark Gregory, MD, J. Michael Pontious, MD, Garfield County Family Practice Residency, Enid, OK; Ronal D. Legako, MD, Keith Underhill, MD, Dan Woiwode, MD, Canyon Park Family Physicians, Edmond, OK; John Pittman, MD, Putnam North Medical Center, Oklahoma City; Paul L. Preslar, DO, Mid-Del Family Physicians, Midwest City, OK; R. Scott Stewart, MD, Family HealthCare Associates, Shawnee, OK; Clinton Strong, MD, El Reno, OK; Terry Truong, MD, Great Plains Family Practice Residency, Oklahoma City.

\section{References}

1. Cacy J, Mold JW. The clinical characteristics of brown recluse spider bites treated by family physicians: an OKPRN study. J Fam Pract 1999;48: $536-42$.

2. Wendell RP. Brown recluse spiders: a review to help guide physicians in nonendemic areas. South Med J 2003;96:486-90.

3. Forks TP. Brown recluse spider bites. J Am Board Fam Pract 2000;13:415-23.

4. Wright SW, Wrenn KD, Murray L, Seger D. Clinical presentation and outcome of brown recluse spider bite. Ann Emerg Med 1997;30:28-32.

5. Blackman JR. Spider bites. J Am Board Fam Pract 1995;8:288-94.
6. Monteiro CL, Rubel R, Cogo LL, Mangili OC, Gremski W, Veiga SS. Isolation and identification of Clostridium perfringens in the venom and fangs of Loxosceles intermedia (brown spider): enhancement of the dermonecrotic lesion in loxoscelism. Toxicon 2002;40:409-18.

7. Elston DM, Eggers JS, Schmidt WE, et al. Histological findings after brown recluse spider envenomation. Am J Dermatopathol 2000;22:242-6.

8. Oespedal KZ, Appel MH, Fillus NJ, Mangili OC, Sanches VS, Gremski W. Histopathological findings in rabbits after experimental acute exposure to the Loxosceles intermedia (brown spider) venom. Int J Exp Pathol 2002;83:287-94.

9. Gebel HM, Finke JH, Elgert KD, Cambell BJ, Barrett JT. Inactivation of complement by Loxosceles reclusa spider venom. Am J Trop Med Hyg 1979;28: 756-62.

10. Gomez HF, Miller MJ, Trachy JW, Marks RM, Warren JS. Intradermal anti-Loxosceles Fab fragments attenuate dermonecrotic arachnidism. Acad Emerg Med 1999;6:1195-202.

11. Maynor ML, Moon RE, Klitzman B, Fracica PJ, Canada A. Brown recluse spider envenomation: a prospective trial of hyperbaric oxygen therapy. Acad Emerg Med 1997;4:184-92.

12. Strain GM, Snider TG, Tedford BL, Cohn GH. Hyperbaric oxygen effects on brown recluse spider (Loxosceles reclusa) envenomation in rabbits. Toxicon 1991;29:989-96.

13. Phillips S, Kohn M, Baker D, et al. Therapy of brown spider envenomation: a controlled trial of hyperbaric oxygen, dapsone, and cyproheptadine. Ann Emerg Med 1995;25:363-8.

14. Lowry BP, Bradfield JF, Carroll RG, Brewer K, Meggs WJ. A controlled trial of topical nitroglycerin in a New Zealand white rabbit model of brown recluse spider envenomation. Ann Emerg Med 2001; 37:161-5.

15. Barrett SM, Romine-Jenkins M, Fisher DE. Dapsone or electric shock therapy of brown recluse spider envenomation? Ann Emerg Med 1994;24:21-5.

16. Burton KG. Nitroglycerine patches for brown recluse spider bites [letter]. Am Fam Physician 1995; 51:1401. 